\title{
Should patients set the agenda for informed consent? A prospective survey of desire for information and discussion prior to routine cataract surgery
}

\author{
Lee Teak Tan ${ }^{1,2}$ \\ Huw Jenkins ${ }^{1,2}$ \\ John Roberts-Harry ${ }^{2}$ \\ Michael Austin' \\ 'Singleton Hospital, Swansea, \\ UK; ${ }^{2}$ West Wales General Hospital, \\ Carmarthen, UK
}

Correspondence: Michael Austin

Department of Ophthalmology, Singleton Hospital, Swansea SA2 8QA, UK

Tel +44 I 792285036

Fax +44 । 792285839

Email mike.austin@swansea-tr.wales.nhs.uk
Purpose: To ascertain the level of information relating to specific risks desired by patients prior to cataract surgery.

Setting: Dedicated cataract surgery pre-assessment clinics of 2 hospitals in South West Wales, UK.

Methods: Consecutive patients (106) were recruited prospectively. Of these, 6 were formally excluded due to deafness or disorientation. Eligible patients (100) were asked a set of preliminary questions to determine their understanding of the nature of cataract, risk perception, and level of information felt necessary prior to giving consent. Those who desired further information were guided through a standardized questionnaire, which included an audio-visual presentation giving information relating to each potential surgical complication, allowing patients to rate them for relevance to their giving of informed consent.

Results: Of the entire group of 100, 32 did not wish to know "anything at all" about risks and would prefer to leave decision making to their ophthalmologist; 22 were interested only in knowing their overall chance of visual improvement; and 46 welcomed a general discussion of possible complications, of whom 25 went on to enquire about specific complications. Of these 25,18 wished to be informed of posterior capsular (PC) tearing, 17 of endophthalmitis, 16 each of dropped lens, retinal detachment and corneal clouding, and 15 of bleeding, sympathetic ophthalmia, and PC opacification.

Conclusion: Patients differ in their desire for information prior to cataract surgery, with one significant minority favoring little or no discussion of risk and another wishing detailed consideration of specific risks. A system of consent where patients have a choice as to the level of discussion undertaken may better suit patients' wishes than a doctor-specified agenda.

Keywords: cataract extraction, informed consent, patient-centered care

\section{Introduction}

The concept of informed consent has evolved over the past century from a judgment in the US Supreme Court in 1914 (Nick 1974) into its current standardized version, whereby healthcare professionals are required to provide adequate information for the patient to make an informed decision on the intended diagnostic or therapeutic procedure. Here "adequate" is based on a presumption as to what "the average" patient wishes to hear or "the average" doctor wishes to elaborate. Perhaps it is timely to address "the individual" patient rather than the average.

Various authors have investigated what patients want to know (Dawes and Davison 1994; Newton-Howes et al 1998) as part of their informed consent in general surgery (Bryne et al 1998; Courtney 2001), ENT (Burns et al 2005), and anesthesia 
(Lonsdale and Hutchinson 1991; Garden et al 1996; Kain et al 1997) but few have considered ophthalmology (Elder and Suter 2004).

Cataract surgery is one of the commonest procedures performed in the United Kingdom (UK) National Health Service (NHS), with around 200,000 operations per year (NHS Executive 2002). In a 10-year analysis of cataract surgery-related claims for negligence in the NHS, more than $50 \%$ involved known complications of cataract surgery and should have been defensible if the risks were adequately explained to the patient before surgery (Bhan et al 2005). This underscores the importance of good doctor-patient communication in the consent process. However, in an increasingly litigious climate, this communication runs the risk of becoming an act primarily to serve the physician's legal defence (Krausher and Steinberg 1986; Fernando et al 2007), undermining other important aspects of patient care. Patients may be burdened with unsolicited information about what might go wrong for the sake of explicit documentation of having being told. This is potentially counterproductive as some studies have shown increased patient anxiety following extensive counseling of risks (Watkins et al 1986; Davis et al 1994; Antrobus 1998), and that too much information may actually prevent the patient from making a reasoned autonomous decision (Epstein and Lasagna 1969; Patten and Stump 1978). In addition some elderly patients may have impaired cognitive function, making comprehension and retention of information difficult (Morgan and Schwab 1986; Lavelle-Jones et al 1993). In such cases, the value of extensive preoperative discussion of complications may be limited and have little bearing in the patients' decisionmaking (Kiss et al 2004). The aim of our study was to investigate patients' desires for information pertaining to cataract surgery in general and to its specific complications.

\section{Patients and methods}

A series of consecutive patients from dedicated cataract surgery pre-assessment clinics of 2 hospitals in South West Wales, UK were recruited prospectively and interviewed by authors LTT and HJ. The survey was administered in 2 parts. The first consisted of preliminary questions (Appendix 1) to determine patients' knowledge of cataract, risk perception, and the level of information desired prior to giving consent. Those who wanted further information pertaining to the surgery and wished to proceed to the second part of the survey were guided through a narrated Microsoft ${ }^{\circledR}$ PowerPoint ${ }^{\circledR}$ audio-visual presentation that served the dual purpose of standardized information package and questionnaire.
Aspects covered in the presentation included explanation of what a cataract is, indications for surgery, progression of cataract without treatment, the surgical procedure itself, postoperative course, chances of visual improvement, and a detailed discussion of specific complications which included explanation in lay terms, an illustrated or animated figure, specific consequences, and incidence. Following description of each complication, patients were asked to rate each complication for its relevance to their giving of informed consent.

\section{Results}

Consecutive patients (106) were identified of whom 6 were excluded as being unable to complete the study due to deafness or disorientation. The 100 patients entered into the study ranged from 22 to 99 years old (mean age 74.7), with $70 \%$ being in their $70 \mathrm{~s}$ and $80 \mathrm{~s}$ (Figure 1); $51 \%$ were male. Of these 100, 65 knew what a cataract was, but 32 thought it was a "film outside the eye", 2 thought it was related to watery eyes, and 1 admitted ignorance. Anatomical knowledge was variable with only $48 \%$ correctly identifying the cornea, $64 \%$ the lens, and $68 \%$ the retina. These results were against a background of all patients having been given standard information, including written, at the time of listing for surgery, typically 4 months previously.

Of the 100 patients, 96 understood that cataract extraction involved an element of risk. Interestingly, of the 4 patients who thought cataract surgery was risk-free, 3 did not want to know anything further, the other only his chances of seeing better. Overall, 32 did not wish to know "anything at all" about risks and indeed would prefer to leave decisionmaking to their ophthalmologist; 22 were interested only in knowing their overall chance of visual improvement; and 46 welcomed a discussion of possible complications. Of these 46 patients who requested further risk discussion, 31 wanted to know "all the possible complications", 5 only the "serious complications", and 10 only the "common complications". Twenty-one patients felt they did not require further discussion of risks beyond the information given in the standard cataract surgery information leaflet. This consisted of a brief "translation" from medical to lay language and included the potential for further surgery and the worst-case scenario of loss of the eye. Twenty-five patients proceeded to watch the audiovisual presentation detailing each specific complication, completing the full survey. A flowchart of patient choices is shown in Figure 2. Of 25 patients who completed the entire presentation relating to specific complications, 18 wished to be informed of 


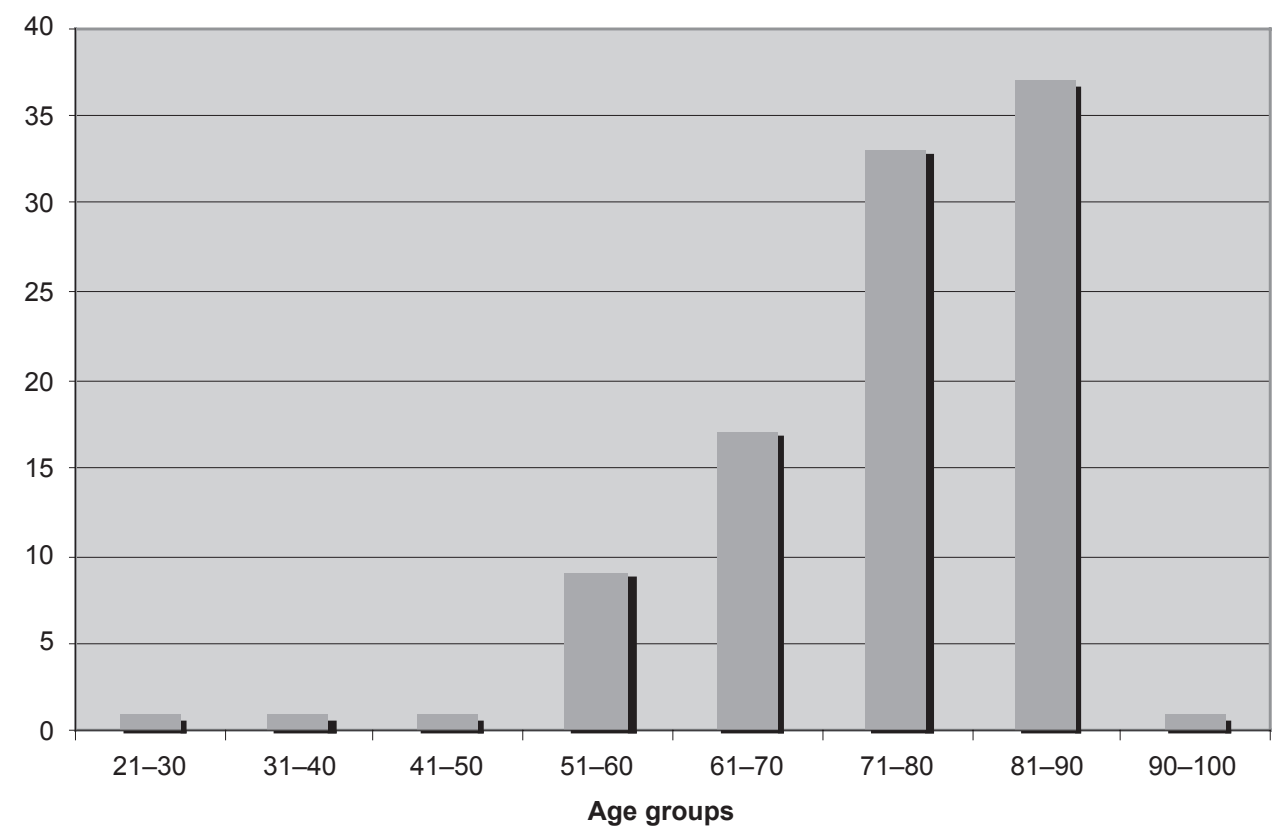

Figure I Age distribution of patients in survey.

posterior capsular tearing, 17 of endophthalmitis, 16 each of dropped lens, retinal detachment and corneal clouding, and 15 of bleeding, sympathetic ophthalmia, and posterior capsular opacification (Figure 3).

\section{Discussion}

The United Kingdom General Medical Council (GMC) guidance document Seeking Patients' Consent (1998, ie, current at the time our study was undertaken) states that doctors "must be satisfied, before providing treatment or investigating a patient's condition, that the patient has understood what is proposed and why, together with any significant associated risks, and has given consent" and they also "should provide patients with appropriate information, which should include an explanation of any risks to which they (the patient) may attach particular significance." Such counsel may be difficult to realize in today's multi-disciplinary, team-based, rapid-throughput ambulatory care cataract surgery where the patient may not even meet their operating surgeon until the day of the operation.

In the UK the yardstick of acceptable practice is measured by the Bolam test (Bolam v Friern Hospital Management Committee [1957]), which states that a doctor is not held negligent if (when informing a patient of the risks and benefits of a procedure) he acts in accordance with a practice accepted at the time as proper by a responsible body of medical opinion even though other doctors may have adopted a different practice. The judge in this case added that even had Bolam succeeded in proving inadequate disclosure of information, in order to succeed in claiming negligence it would have to be established that the giving of additional information would have resulted in refusing consent to treatment. In the context of the present study such a claim would be difficult to prove in a patient faced by visual loss due to cataract. The Bolam principle was reinforced by the decision of the House of Lords in the case of Sidaway (Sidaway v Bethlem Royal Hospital Governors [1985]), where the court rejected a negligence claim against a neurosurgeon for failing to inform of the risk of paraplegia from cervical cord decompression (which occurs in less than $1 \%$ of cases) on the grounds that this practice was in accordance with a responsible body of medical opinion. Although Bolam prevailed in Sidaway, the debate on informed consent continues, including increased emphasis on the desires of the "reasonable patient" as in Roger $v$ Whitaker (1992) where relevant information on a rare complication of bilateral blindness was withheld from a patient voicing specific concern as to the likelihood of total bilateral visual loss - hence the doctor being found negligent for not discussing sympathetic ophthalmia (a risk of 1 in 14,000).

With any shift in the approach to consent from that of the reasonable physician to that of the reasonable patient there is a commensurate challenge to supply adequate information to patients with an emphasis on comprehensive discussion of risks. If clinicians decide it is invariably their role to set the agenda for the discussions relating to consent then they will 


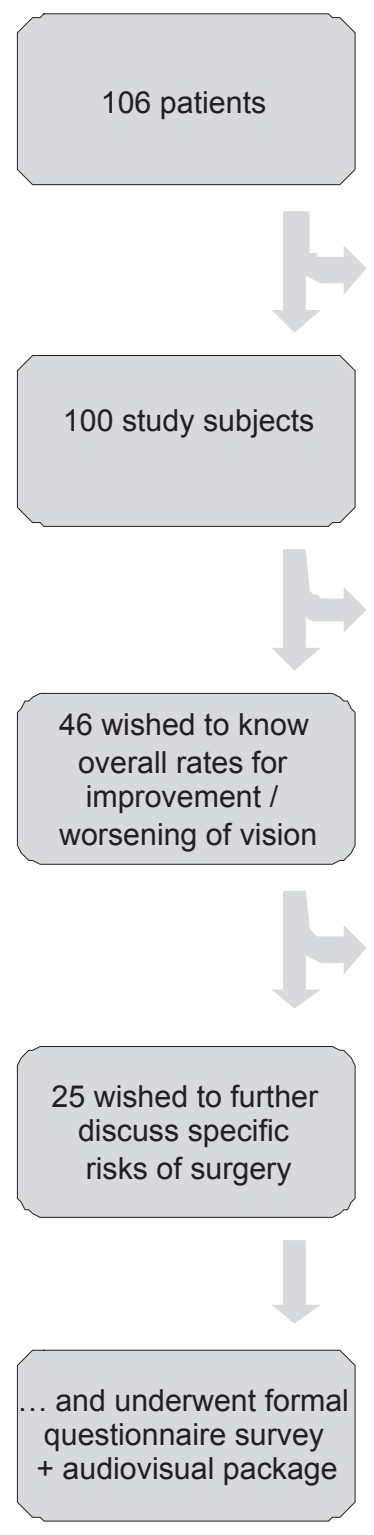

6 patients excluded-

deafness / disorientation

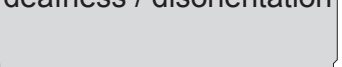

54 stated no wish

to further discuss

risks of surgery

21 stated no wish to further discuss specific risks of surgery

Figure 2 Flowchart of patient choices.

inevitably generate their own dilemma as to what patients want to know and how they wish to discuss risks and benefits issues. Elder and Suter (2004) found that patients desire information on the chances of visual improvement after cataract surgery, its time course, the risk of losing vision, the consequences of not having surgery, and the types of serious complications. Over half of their patients wished to be informed of a risk of 1 in 1000. In a study by Burns et al (2005), nearly three quarters of patients expected to be informed of all known complications even if the rates were less than $1 \%$. However, when questioned postoperatively, over half could not list even one complication of the procedure.

In our study, less than one third of patients expressed a desire to be informed of all complications, and following detailed explanation only an average of $16 \%$ decided that it was important to be informed of specific complications of cataract surgery. Interestingly, a significant third did not want to know anything at all and wished to leave the decision-making to the doctors, reflecting a high level of trust and an assumption that doctors act in the best interests of their patients. This finding is consistent with a previous study of cataract surgery by Kiss (2004) in which $44 \%$ of their patients preferred a physician-dominated decision, the prevailing preoperative attitude being one of "believing in and hoping for the best". A likely explanation for this is a subconscious effort on the part of the patients to avoid "cognitive dissonance" (ie, declining any negative information which is in conflict with the positive associations of their 


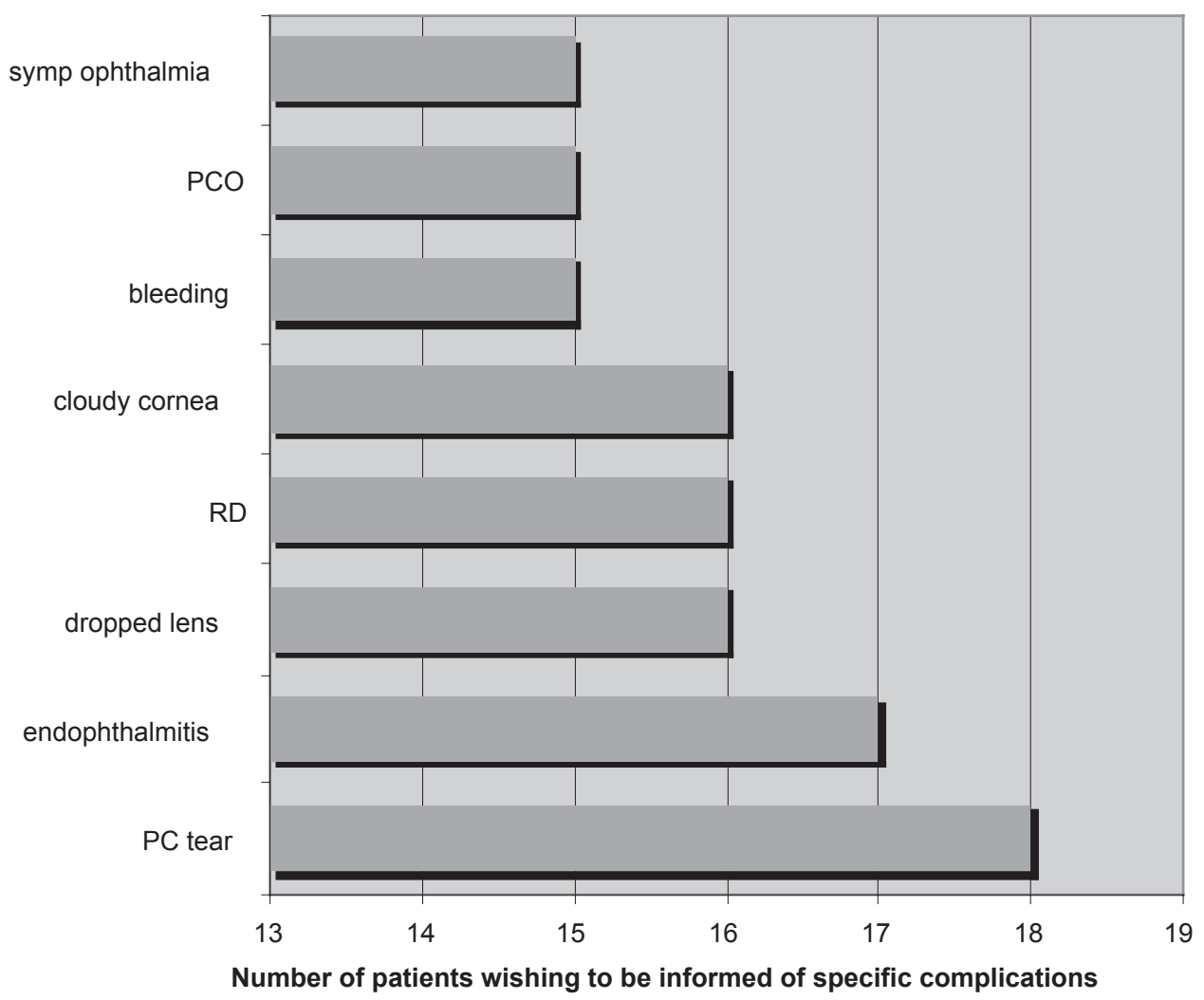

Figure 3 Attitude to specific complications.

Abbreviations: PC, posterior capsular; PCO, posterior capsular opacification; RD, retinal detachment.

existing decision to proceed). Four patients of 100 in our study had the misconception that cataract surgery is risk-free. On being informed that there was indeed a risk they declined further discussion - their prerogative. Thus while it is necessary to emphasize that surgery carries some risk, and discuss in broad terms the consequences of complications, including loss of vision or the eye, our study would suggest that it may be unnecessary to discuss each specific complication with every patient unless this is their wish.

Although of relevance, the lack of informed consent is usually not the main issue in litigation. In a majority of cases, it is the lack of an immediate and full explanation following occurrence of a complication or a delay in diagnosis and appropriate management resulting in adverse outcomes that prompted patients to file for malpractice. In a 10-year period, claims related to endophthalmitis incurred the largest amount of indemnity paid by OMIC (Ophthalmic Mutual Insurance Company), a single-specialty insurer in the US, and comprised the largest percentage of claims in any group resulting in an indemnity payment (Brick 2004). Yet this is a complication of cataract surgery that is invariably mentioned during the consent process. Informed consent provides no defence if the treatment was indeed negligent or ill-advised and any complication not managed appropriately. The corollary, that a claim is indefensible if the complication is not aforementioned, is also unsubstantiated. For a claimant to be successful, the question of causation needs to be answered and subjected to logical analysis as in the Bolitho Judgement (Bolitho $v$ City and Hackney HA [1998]): "Would the patient have undergone the procedure had he been told of the risk of that particular complication?" If it is the expressed choice of a patient to refuse information pertaining to specific complications on the basis that they have understood the risks they consider relevant in broad terms to make an informed decision and that further explanation of specific complications would not change their decision to proceed with surgery, doctors are not culpable by respecting that choice, which should be recorded in a suitably designed care pathway. This approach to consent has recently been formalized in the latest publication from the United Kingdom General Medical Council (2008). Informed consent is not the signing of a document following a litany of complications; it should constitute a process by which the intended surgery is discussed with each patient as an individual, addressing their specific needs and concerns. 
From our series of 100 patients we would conclude that when given a choice fewer than half of our patients wished to be informed of specific risks of cataract surgery and only one quarter would undergo a detailed discussion of such risks, less than two thirds of whom felt it was important to be informed of each individual risk associated with the procedure. In view of our findings and the above discussion, we would advocate wider patient choice. Individuals who have mental capacity should be allowed to choose how they give consent and thus determine the agenda for the consent discussion rather than be subjected to information they do not wish to hear (Davies 2005). British medicolegal opinion should consider that the doctor-patient relationship is fiduciary (Brazier 2003), where the doctor and patient are empowered to agree upon the information that needs to be exchanged in order to realize consent for treatment. One size need not fit all.

\section{Disclosures}

The authors have not received financial support for the study and have no proprietary interest in any products mentioned.

\section{Note}

Presented to the European Society of Cataract and Refractive Surgeons (ESCRS), Stockholm, September 2007.

\section{References}

Antrobus HL. 1988. Anxiety and informed consent. Anaesthesia, 43:267-9.

Bhan A, Dave D, Vernon SA, et al. 2005. Risk management strategies following analysis of cataract negligence claims. Eye, 19:264-8.

Bolam v Friern Hospital Management Committee (1957) 2 AII ER 188.

Bolitho v City and Hackney HA (1998) 9 MLR 26 (HL).

Brazier M. 2003. Medicine, patients and the law. 3rd ed. London: Penguin Books. p. 110.

Brick D. 1997. Risk Management Lessons From a Review of 168 Cataract Surgery Claims. Surv Ophthalmol, 43:356-60.

Bryne DJ, Napier A, Cuschieri A. 1988. How informed is signed consent? BMJ, 296:839-40.
Burns P, Keogh I, Timon C. 2005. Informed consent:a patients' perspective. J Laryngol Otol, 119:19-22.

Courtney MJ. 2001. Information about surgery:what does the public want to know? Aust N Z J Surg, 71:24-6.

Davis TMA, Maguire TO, Haraphongse M, et al. 1994. Preparing adult patients for cardiac catheterization:informational treatment and coping style interactions. Heart Lung, 23:130-9.

Davies J. 2005. Doctors should be allowed to offer patients a simplified form of consent, expert says. BMJ, 331:925.

Dawes P, Davison P. 1994. Informed consent:what do patients want to know? J Royal Soc Med, 87:149-52.

Elder MJ, Suter A. 2004. What patients want to know before they have cataract surgery. Br J Ophthalmol, 88:331-2.

Epstein LC, Lasagna L. 1969. Obtaining informed consent:form or substance. Arch Intern Med, 123:682-8.

Fernando B, Bhojwani R, Skarmoustas P, et al. 2007. Standards in consent for cataract surgery. J Cataract Refract Surg, 33:1464-8.

Garden AL, Merry AF, Holland RL, et al. 1996. Anaesthesia information what patients want to know. Anaesth Intensive Care, 24:594-8.

Kain NZ, Wang SM, Caramico LA, et al. 1997. Parental desire for perioperative information and informed consent:a two-phase study. Anesth Analg, 84:299-306.

Kiss CG, Richter-Mueksch S, Stifter E, et al. 2004. Informed consent and decision making by cataract patients. Arch Ophthalmol, 122:94-8.

Kraushar MF, Steinberg JA. 1986. Informed consent. Arch Ophthalmol, 104:352-5.

Lavelle-Jones C, Bryne DJ, Rice P, et al. 1993. Factors affecting quality of informed consent. $B M J, 306: 885-90$.

Lonsdale M, Hutchinson GL. 1991. Patients' desire for information about anaesthesia. Scottish and Canadian attitudes. Anaesthesia, 46:410-2.

Morgan LW, Schwab IR. 1986. Informed consent in senile cataract extraction. Arch Ophthalmol, 104:42-5

Nick WV. 1974. Informed consent - the new decisions. Bull Am Coll Surg, 59:12-17.

Newton-Howes PAG, Bedford ND, Dobbs BR, et al. 1998. Informed consent: what do patients want to know? NZ Med J, 111:340-2.

(NHS) National Health Service Executive. 2002. Action on cataracts. NHS executive, Department of Health UK.

Patten BM, Stump W. 1978. Death related to informed consent. Tex Med 78:49-50.

Roger v Whitaker (1992) 16 148, Aust HC.

Sidaway v Bethlem Royal Hospital Governors (1985) AC 871.

United Kingdom General Medical Council. 1988. Seeking patient's consent: The ethical considerations. London.

United Kingdom General Medical Council. 2008. Consent: patients and doctors making decisions together. London.

Watkins LO, Weaver L, Odegaard V. 1986. Preparation for cardiac catheterization:tailoring the content of instruction to coping style. Heart Lung, 15:382-9. 
Appendix I Screening questionnaire for cataract surgery consent survey.

1. Can you hear me?

2. Mental state screen

What is the date and time?

What is this place?

What is my job?
YES (continue)

NO ..... (exit)

$\begin{array}{ll}\text { CORRECT ..... } & \text { (continue) } \\ \text { CORRECT ..... } & \text { (continue) } \\ \text { CORRECT ..... } & \text { (continue) }\end{array}$

INCORRECT ....(exit)

INCORRECT .... (exit)

INCORRECT .... (exit)

3. What is a cataract? (all continue)
.... $\quad$ A - A film on the outside of the eye
.... B - Clouding of the lens
.... $\quad$ C - Watering of the eye
.... D - Redness of the eye

4. Are you aware that cataract surgery (in addition to having a good chance of improving your vision) also involves an element of risk to your sight?

$$
\text { YES ..... (continue) }
$$

NO ..... (continue)

5. How much would you like to know about the risks of your operation?

$\begin{array}{lll}\ldots . . & \text { A }- \text { Nothing at all }- \text { I'll leave it all to the doctors } & \text { (exit at this point) } \\ \ldots . . & \text { B }- \text { Only my chances of seeing better } & \text { (exit at this point) } \\ \ldots . . & \text { C }- \text { My chances of seeing better and worse } & \text { (continue) } \\ \ldots . . & \text { D }- \text { What the doctor thinks I ought to know } & \text { (continue) }\end{array}$

6. Of the things that may go wrong, what would you like to know? (all continue)

$$
\begin{aligned}
& \ldots . . \quad \text { A }- \text { Only the most serious complications (for example loss of sight) } \\
& \ldots . . \\
& \text { B... B }- \text { Only the commonest complications } \\
& \text { C. C - Both common and serious complications }
\end{aligned}
$$

7. Do you wish to hear some more information about specific risks of cataract surgery and take part in a survey regarding these risks?

$$
\text { YES ..... (continue) }
$$$$
\text { NO ..... (exit) }
$$

8. Can you read this writing? (show then the presentation on screen)

$$
\text { YES ..... (continue) }
$$

NO ..... (exit) 
